\title{
ANN Application of the APF Improved for DG Unit System Reliability
}

\author{
T.Santhosh kumar ${ }^{1}$, Dr.J.Shanmugam ${ }^{2}$ \\ \{santhoshkmr562@gmail.com1,jshanmugam@yahoo.com²

\begin{abstract}
Research Scholar Dept of EEE, Bharath Institute of Higher Education and Research, Chennai, Tamil Tamil Nadu India. ${ }^{2}$
\end{abstract} \\ Nadu India. ${ }^{1}$, Professor Dept of EEE, Bharath Institute of Higher Education and Research, Chennai,
}

\begin{abstract}
Generally, Power Quality is the chiefworry in the present power system. It mainly effects due to sudden changes in load, other environmental conditions. Power Quality main effects on system voltage and current. To compensate the problems in system voltage a series active filter is proposed and also for mitigating system currents a active shunt filter is implemented. The gate signals required for series and shunt filters is designed with help of system parameters and dc-link voltage of filter. To get better quality and harmonic distortion, an artificial neural network is executed to control the dclink voltage of both filters. This system is verified using Matlab/Simulink and evaluated the results with conventional controller.
\end{abstract}

Keywords: 3-Level Inverter, ANN Controller, Series and shunt active Filters, Power Quality and Harmonic Distortion..

\section{Introduction}

In recent years, vegetation associated fossil energy like petroleum coal and gas offers a vital position to convene the load requirement. The key problem associated with above vegetation is this vegetation might source the global affectionate, contamination and discharges carbon di-oxide which is unsafe to living things and foliage. The renewable energy scheme is the answer to power stations to conquer above tribulations. The suitable consistent DG systems are Photo Voltaic and storm as liberally accessible in environment, vastly competent and cost-effective [1].

The distributed energy system is used to drive dissimilar load circumstances. The discrepancy in load alters causes unbalanced power operation which affects the power quality of the power system. This power quality affected in view of voltage and current quality [2]. These papers focused to enhance the power quality perfection by reducing the harmonics in system currents affected due to load variation. To nullify these troubles, a convention power tool called as active filters is employed to grid allied DG scheme. The managing structure for these filters is intended with the dc-voltage manager and reference currents for three phase system are created using unit vector practice. Also, the Artificial Neural Network (ANN) planner scheme is recommendable to normalize the dc-voltage of CPD to progress the power quality [3]. For higher-voltage and higher-power appliances, multi-level inverter takes part in a chief role and contains more advantages compared to existing inverters. These inverters progress the potential superiority and ability to decrease the over voltage stress. Currently, 
multilevel inverters raised more striking for design engineers due to its benefits compared to existing three-level pulse width-modulate (PWM) inverters. This work focused the implementation of series and shunt active filters in neutral-point clamped (NPC) based multilevel inverter. A PWM controller is designed for proposedNPC converter to obtain correct switching outline.

\section{Proposed system:}

A mixture of high power electronic tool works as a regulator and a condenser works as a nullifier named as tradition power device (CPD) is used to provide a eminence of power to clients [8]. This converters are intended as potential resource converters mostly, due to itsability of self-supporting of dc-bus potential controller. CPD are broadly categorized into two types such as a) balance form and b) network structural type.

In general, the power superiority troubles happenmostly due to dissimilarity of load, system constraints and on off circumstances. In present work, the grid scheme with PV is designed and functional to operate for dissimilar load circumstances such as, uneven and nonlinear loads. The subsequent are the categorizations of nullifying type CPD's a) Series Filter, b) Shunt Filter. To nullify the transients generated with uneven non-linear loads both sequence and parallel controllers [8] [9] are designed in this paper. The construction of proposed system is shown in figure 1.

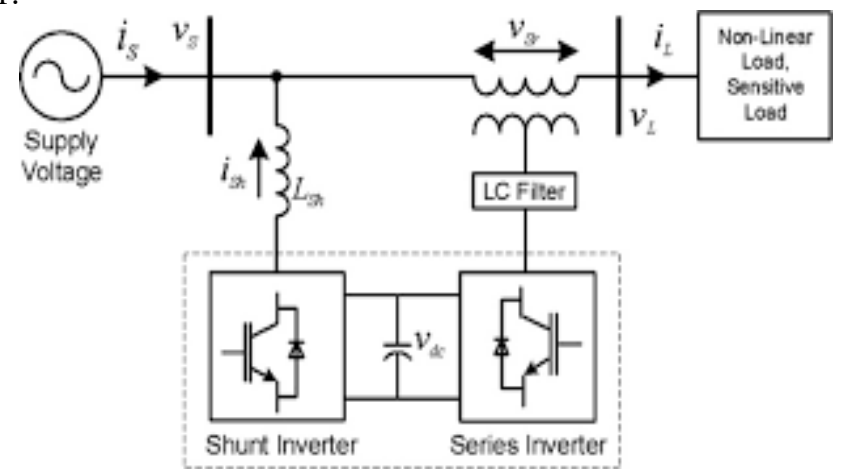

Figure 1 Block diagram of grid linked Shunt and Series inverter with SPF.

\section{NPC Topology:}

Figure2. shows the methodology proposed in NPC three-stage inverter with LC channel at the yield side. Each leg in the design contains four IGBTs associated in arrangement [10] [11]. The NPC-3 stage inverter utilizes two divided capacitors in arrangement for DC connection, and creates zero voltage level. In this manner, the voltage fall on the IGBT will be $\mathrm{U}_{\mathrm{dc}} / 2$ which is one-a large portion of that of the regular two-stage inverter, where $U_{\mathrm{dc}}$ is the all out potential of DC connects. This element creates is progressively appropriate for the application with higher DC transport potential. Furthermore, the NPC inverter has a fewadditional great highlights together with lower basic mode voltage and lower yield current wave for a similar 
exchanging recurrence contrasted and the traditional two-level inverter [12]. Thus, a littler yield channel is required contrasted with an equal evaluated two-stage inverter.

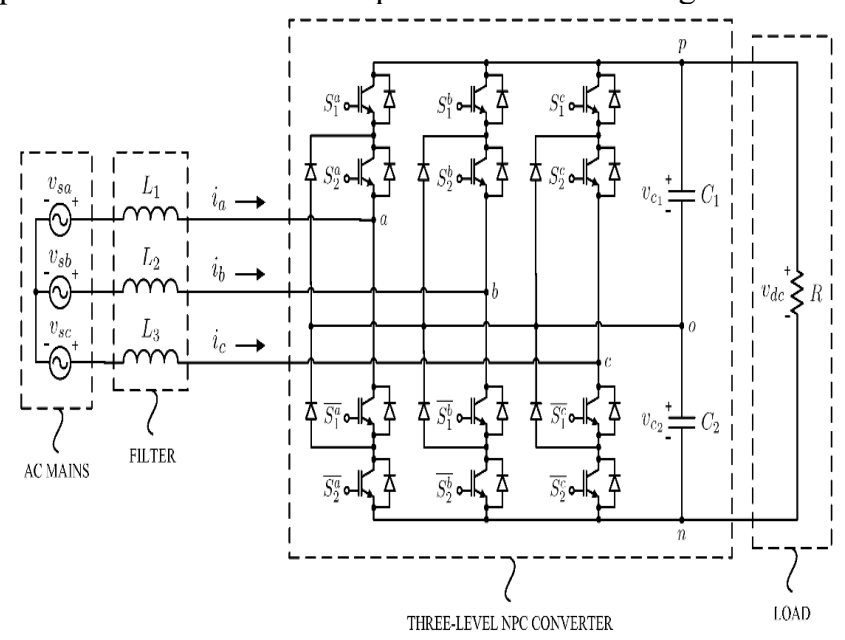

Figure 2: The NPC three-stage inverter topology

\section{Active Series Power Filter:}

The design of active series filter is shown in figure 3. The design circuit comprises the three stage NPC, a series insertion transformer and coupling capacitor. Neutral point converter is employed to produce three stage potentials and organizing scheme voltages for various loadcircumstanceslike sag and swell and potential turbulence.

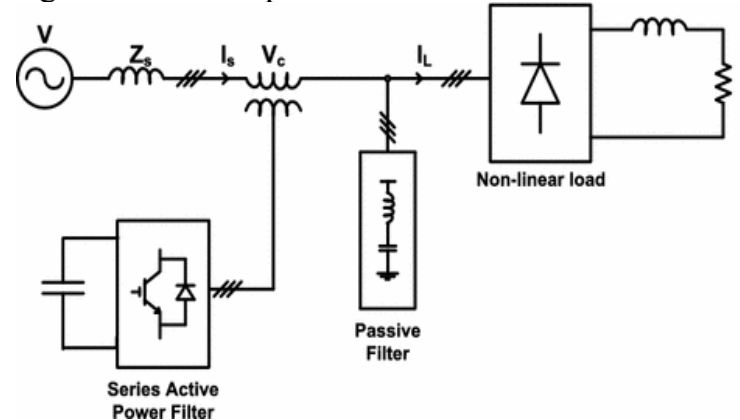

Figure 3: Design of active series filter

The series controller is designed and employed to manage the oscillations in the system potentials like sag, swell and turbulences. The control signals are necessary for series controller which aids to producethe dc-link voltages of the APF and grid potentials. These generated potentials are converted in to multiple-phase coordinate i.e, dq-axis casing. After necessary evaluation of these voltage signals are given to PWM converter to produce input signals [13]. The designed arrangement of active series filter control scheme is observed in figure 4 . 


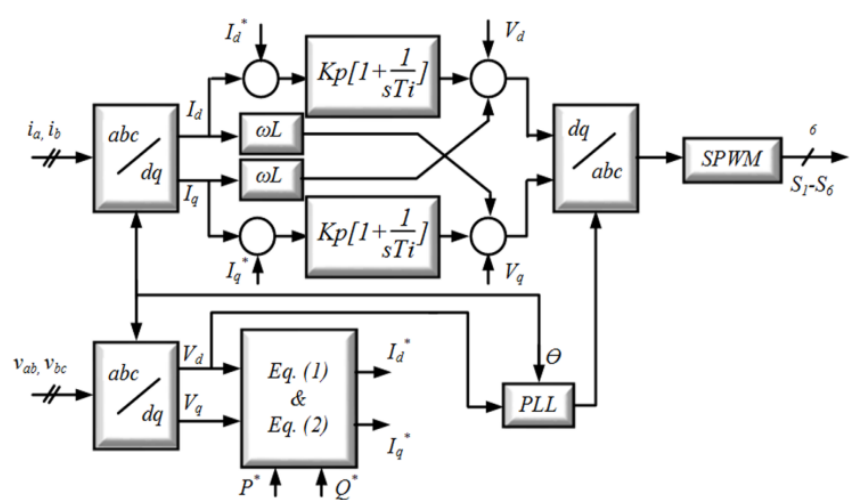

Figure 4: Design structure scheme of PSO base GSC manage diagram

The potential conceded in cause and load current of single stage may be uttered in the subsequent equations,
$V_{s}(t)=V_{m} \cos \cos \omega_{s} t$
$I_{\propto 1}(t)=I_{\propto 1} \cos \cos \omega_{s} t$

The nullifying current provided by active power shunt filter is written as,

$i_{c}(t)=i_{L}(t)-i_{\propto 1}(t)=i_{L}(t)-I_{\propto 1} \cos \cos \omega_{s} t(3)$

\section{Shunt APF controller}

The Shunt APF is solitary of the elements in parallel APF organizer unit. It consists of a capacitor along with VSI converter allied in parallel in connection by existing system. The reason of application of shunt APF in circuit system is to obtain the nullified bus potential sag by getting or supplythe reactive power in distribution system. The design diagram of shunt APF is observed in figure 5 .

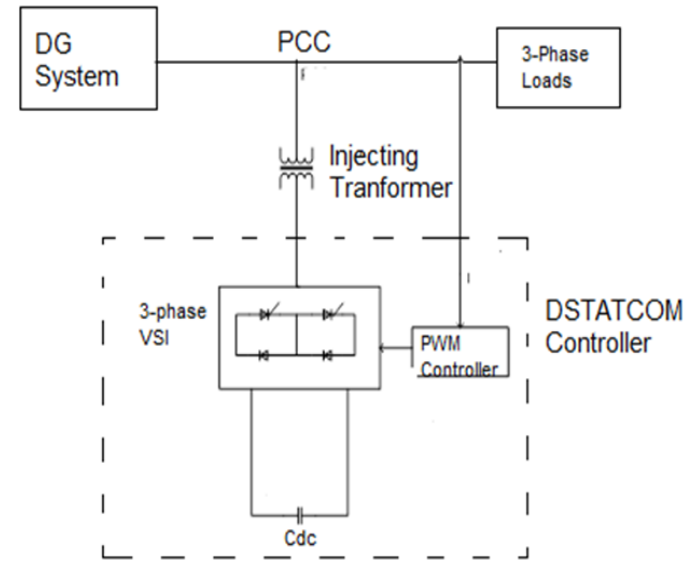

Figure 5: Shunt inverter control structure 


\section{ANN Controller}

The present work is also aimed to design and application of stabilized active shunt power filter using ANN by back proliferation algorithm. ANN is an artificial neural network mayreplicates theorganicintelligence system. Basic principle of ANN scheme is shown in the following figure 6 ,

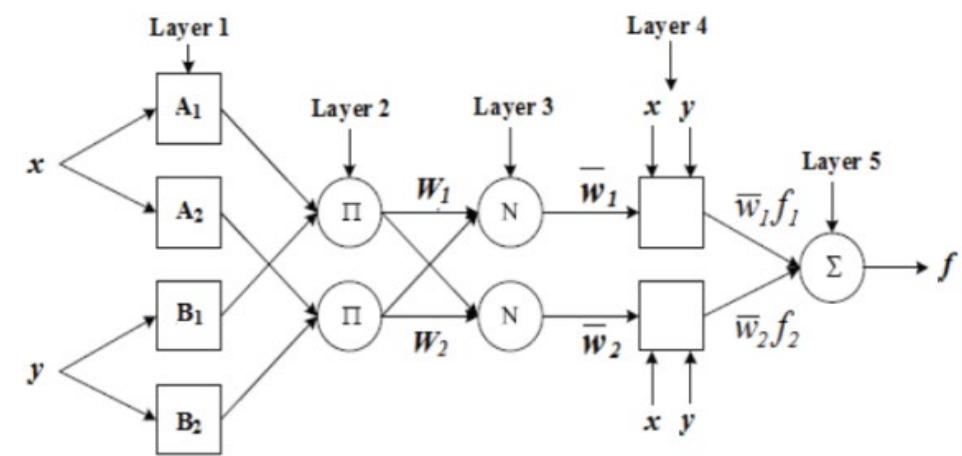

Figure 6: Design Architecture of Artificial Neural Network

Figure 6 shows the artificial neural network architecture. In this paper, feed forward neural network is chosen.

There are numerousmethods have been employed for controlling the SAPF, among that all ANN control scheme have the advantages as fairly accurate utility mapping, high amount of fault lenience with little calculation time. In the organizing tactic, the DC capacitor was examined and offered with the given allusion value. The designfiguredemonstrates the functioning main of active shunt power filter with ANN controller.

The input in the proposed ANN is uttered by the equation and is specified to the position exchanger.

$u=\left[V_{d c}^{*} V_{d c}\right]^{T}$

Couple of states is generated by the creator block, $X_{1}$ and $X_{2}$ as follows,

$X_{1}=V_{e}(k)$

$X_{2}=\frac{\delta X_{1}}{\delta k}$

Where $V_{e}(k)=V_{d c}^{*}-V_{d c}(k)$ and $Z_{(k)}$ is the output error embody as,

$Z_{(k)}=V_{0}(k)-V_{0}(k-1)$

The output $V_{0}(k)$ is fed back to the output state to estimate $I_{\propto 1}$.

Scheming signal is produced by the Neuron cells through consistentmeeting as,

$u(k)=u(k-1) \sum_{i=1}^{2} \quad W_{i}(k) x_{i}(k)$

Here Wi referred as weight of the scheme. Neuron at kth moment achieve by exercising neuron via hebb's rule [11], is specified as follows,

$W_{i}(k+1)=(1-c) W_{i}(k)+\eta r_{i}(k)$

$r_{i}(k)=z(k) u(k) x_{i}(k)$ 
Here $r_{i}$ - Progressive gesture

$\eta$ - Hebb's study ratio

$c$ - Constant

Substituting (4) and (5) to the equation (3), then

$\Delta W_{i}(k) i(k)=W_{i}(k+1)-W_{i}(k)=-c\left[W_{i}(k)-\eta z(k) u(k) x_{i}(k) / c\right.$

Weight at the $k^{\text {th }}$ step is given in $\Delta W_{i}(k)$.Based on the Hebbs assumption, weights of the neurons are tuned. Weights are represented by,

$W_{1}(k+1)=W_{1}(k)+\eta I^{z}(K)+x_{1}(k)$

$W_{2}(k+1)=W_{2}(k)+\eta I^{z}(K)+x_{2}(k)$

Assessment of the balanced current finished by the control stricture whenever the ANN[12], begins working. These initialization of ANN organize constraints using offline type training is shown in figure 7

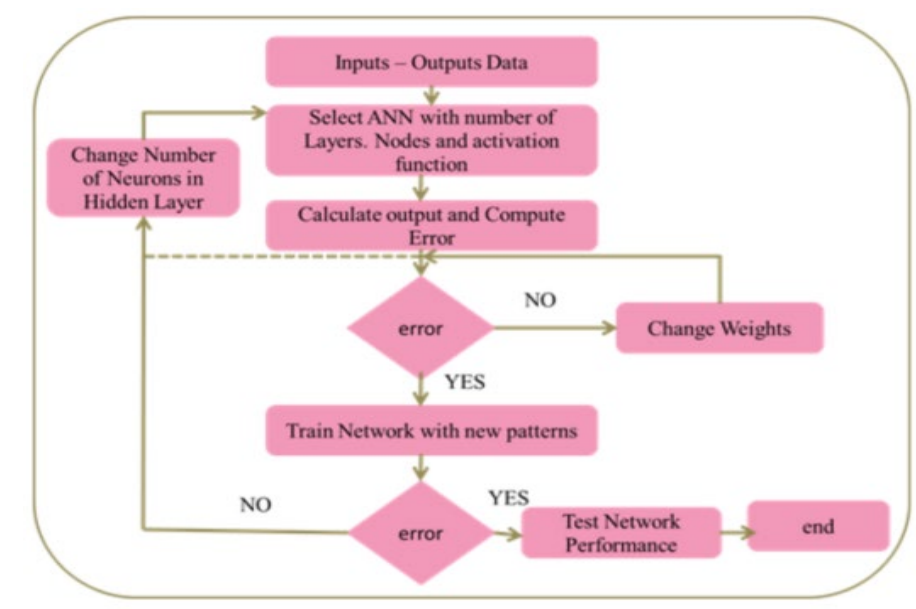

Fig7. Flow chart of the ANN algorithm.

These networks basically contains of three stages explicitly input layer, hidden layer and output layer. The inputs of ANN is called neurons [14] [15]. Here, each input is divided into 5 neuron values named as $\{\mathrm{MP}, \mathrm{SP}, \mathrm{Z}, \mathrm{SN}, \mathrm{MN}\}$. This neurons at input layer is occupied with weights and bias to generate outputs. The outputs at first stage is acts inputs to the second stage and then to third stage (output stage). After train the feed forward network, the simulation block will generate with the help of 'gensim' command [16].

\section{Simulation Results \&Discussions}

The projected work is implemented in Matlab/Simulation software tool and the corresponding simulation results are observed in figure 8 to 23 . 


\section{Case-1: With PI Controller}

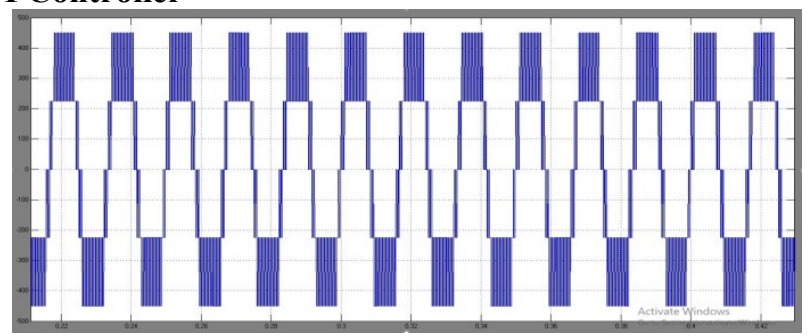

Figure 8: Three level voltages of proposed converter

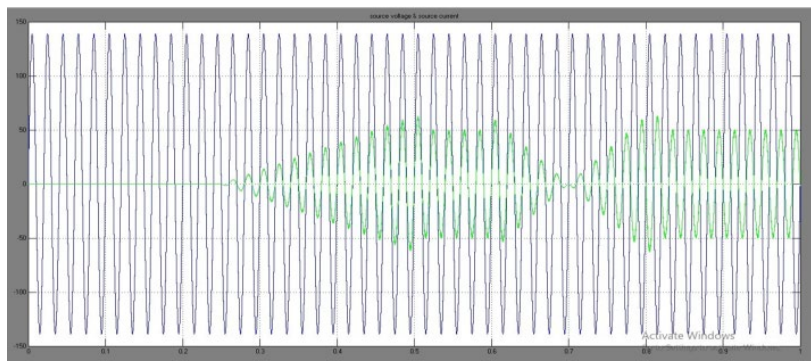

Figure 9: Source potential \& Current with Three Level Series and Shunt Converter with PI Control System

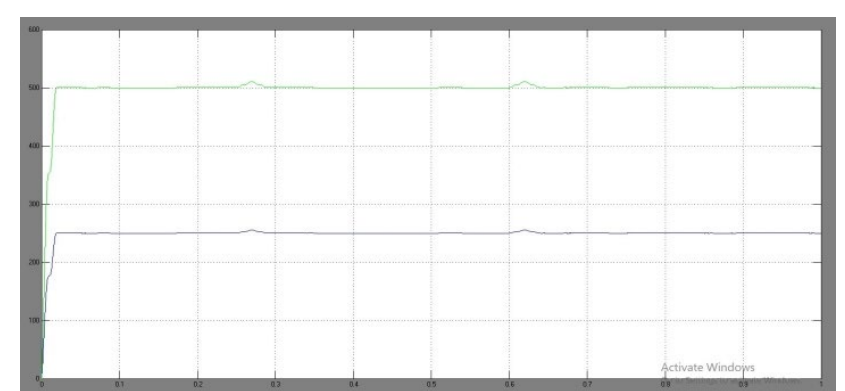

Figure 10: Dc potential of series \& shunt converters

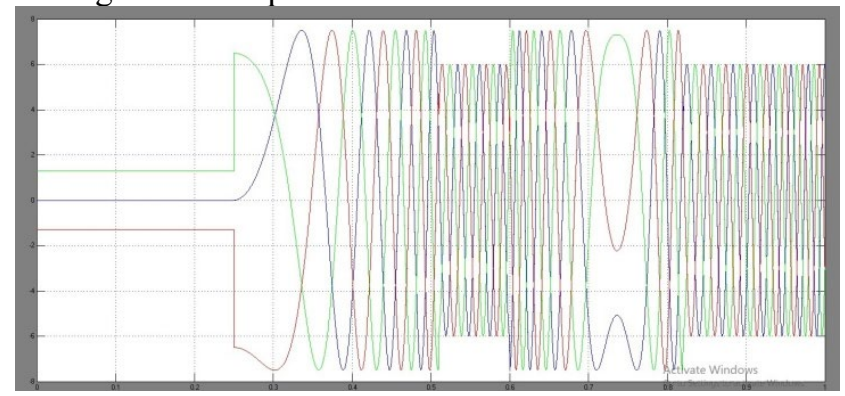

Figure 11: Unbalanced load currents at motor using PI controller 


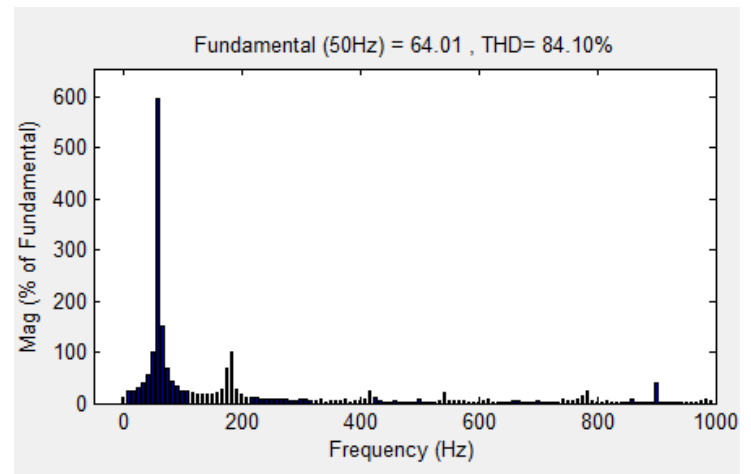

Figure 12. THD for NPC potential using PI Controller without SPF

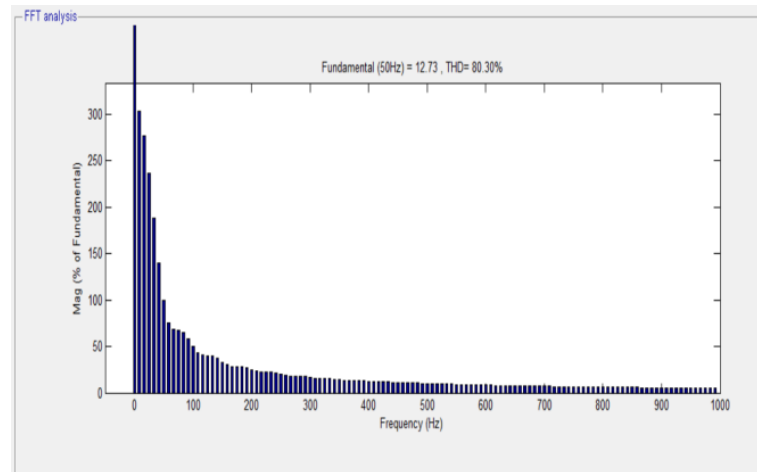

Figure 13: Figure 12: THD for NPC potential using PI Controller with SPF

\section{Case-2: With Fuzzy Controller}

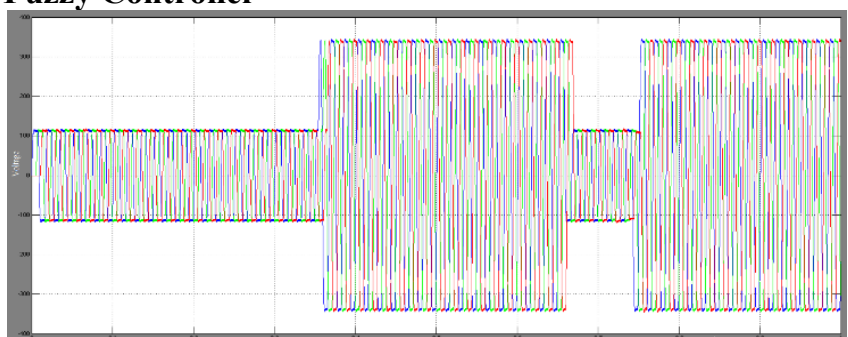

Figure 14: Series \& Shunt Converter voltages using FUZZY Control System without SPF 


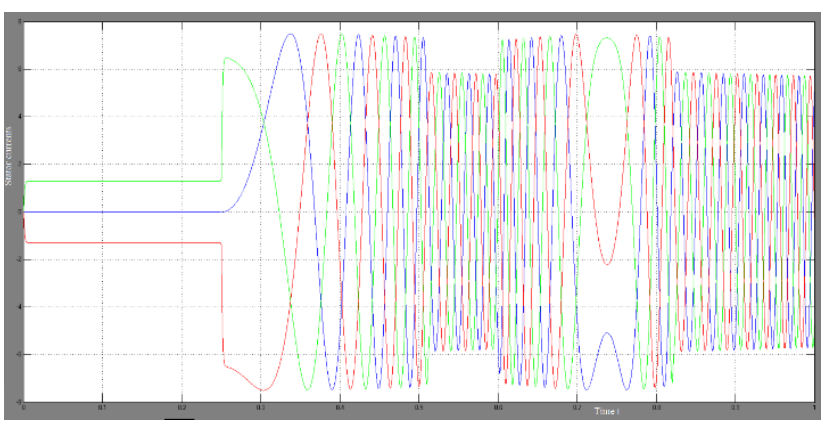

Figure 15: Unbalanced load currents at motor using FUZZY controller

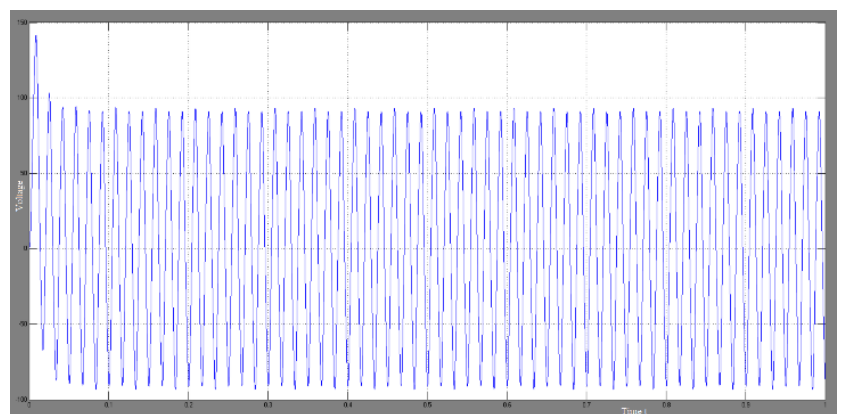

Figure 16: Series \& Shunt Converter voltages using FUZZY Control System with SPF

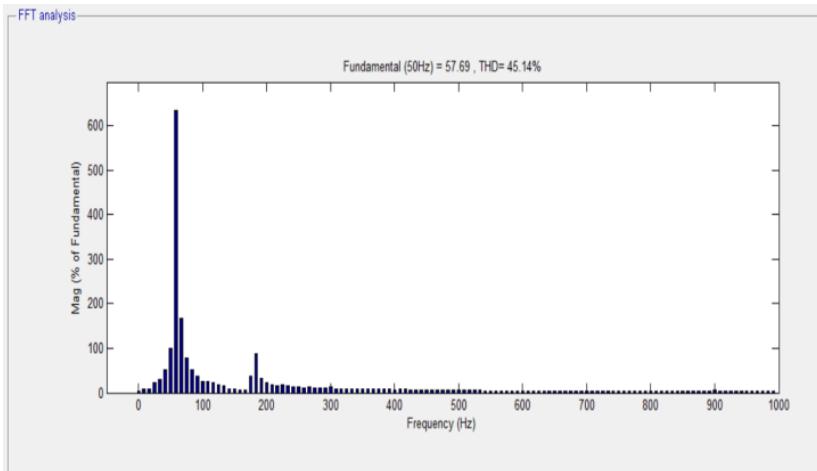

Figure 17: THD for NPC voltage using FUZZY Controller without SPF 


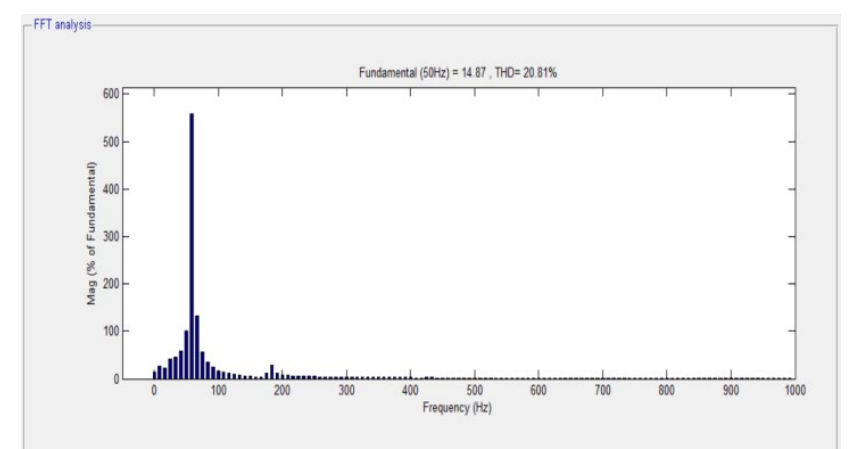

Figure 18: THD for NPC voltage using ANN Controller with SPF

\section{Case-3: With ANN Controller}

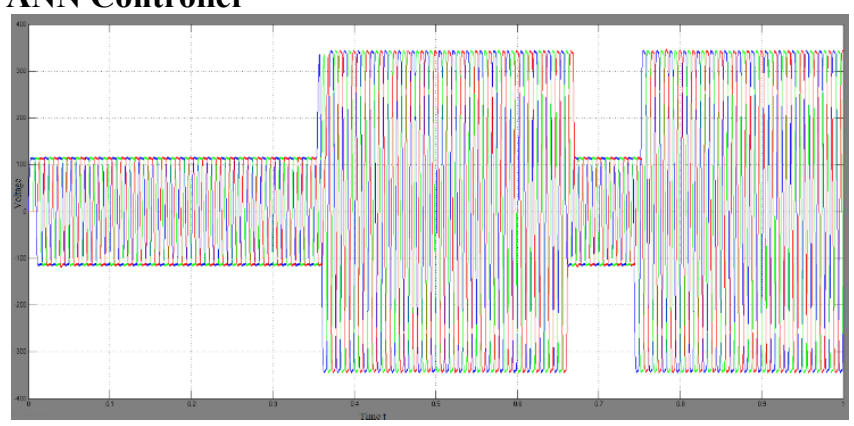

Figure 19: Series \& Shunt Converter voltages using ANN Control System without SPF.

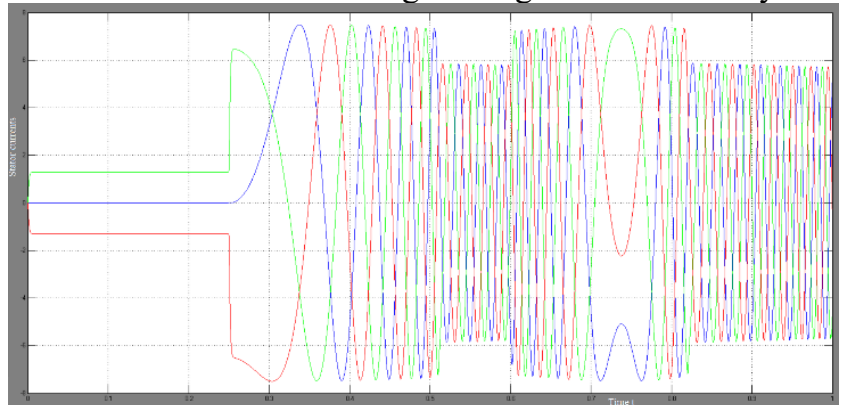

Figure 20: Unbalanced load currents at motor using ANN controller

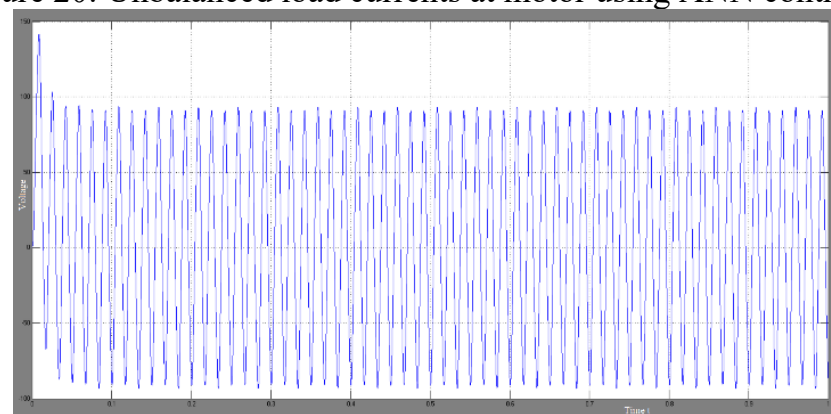

Figure 21: Series \& Shunt Converter voltages using ANN Control System with SPF 


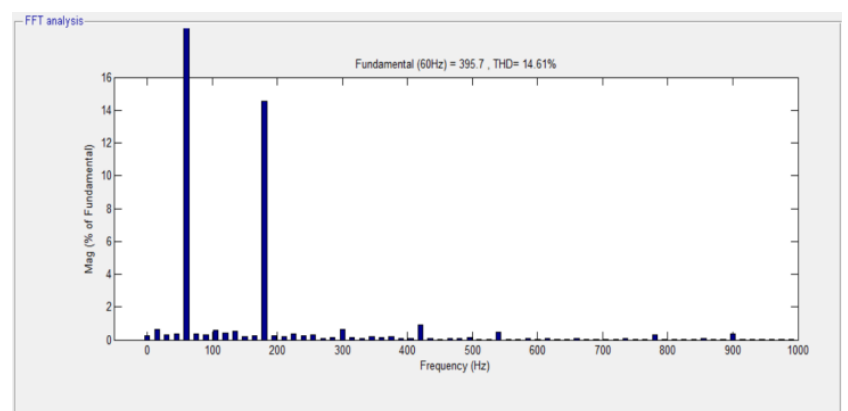

Figure 22: THD for NPC voltage using ANN Controller without SPF

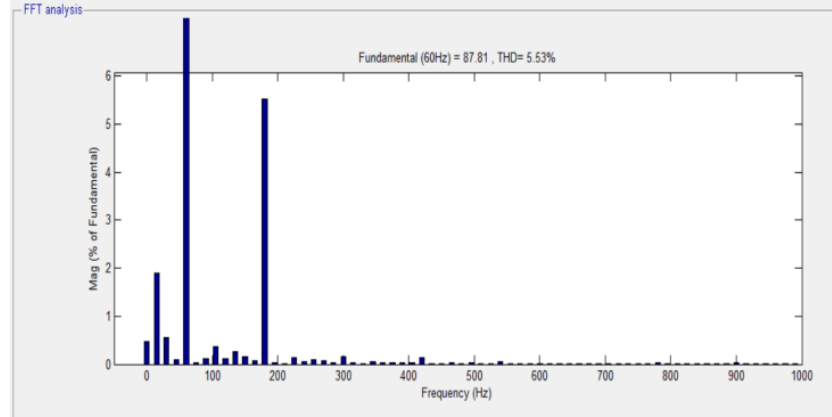

Figure 23: THD for NPC voltage using ANN Controller with SPF

\section{CONCLUSION:}

To achieve enhanced improved power quality of distributed system, an ANN based active series and shunt filters are implemented in this paper. To achieve improve voltage imbalances the series and shunt converters are designed by using 3-level neutral point clamped converters.

Table I Comparisons of THD using different controllers and with shunt and series SPF.

\begin{tabular}{|l|l|l|}
\hline Controllers & Without SPF & With SPF \\
\hline PI & $84.10 \%$ & $80.30 \%$ \\
\hline FUZZY & $45.14 \%$ & $20.41 \%$ \\
\hline ANN & $14.61 \%$ & $5.53 \%$ \\
\hline
\end{tabular}

The organizing illustration for couple of filters is executed using dc-link potential and structure constraints. To achieve enhanced power eminence of the designed system, the control structures are employed by 1) conservative PI manager 2) Fuzzy regulator and 3) ANN organizer. The simulation outcomes carried out shown under variable load conditions. From the results presented above, the ANN based design structure system provides superior power quality in comparison of existing PI and Fuzzy controllers. 


\section{References}

[1] T. S. Kumar, M. R. Nayak, R. V. Krishna and K. P. Rao, "Enhanced Performance of Solar PV Array-Based Machine Drives Using Zeta Converter," 2020 IEEE International Conference on Advances and Developments in Electrical and Electronics Engineering (ICADEE), Coimbatore, India, 2020, pp. 1-5, doi: 10.1109/ICADEE51157.2020.9368937.

[2] V. G. Agelidis, D. M. Baker, W. B. Lawrance, and C. V. Nayar, "A multilevel PWM inverter topology for photovoltaic applications,” in Proc. Int. Symp. Ind. Electron., Jul. 1997, vol. 2, pp. 589-594.

[3] G. J. Su, "Multilevel DC-link inverter," IEEE Trans. Ind. Appl., vol. 41, no. 3, pp. 848-854, May-Jun. 2005.

[4] M. Calais, L. J. Borle, and V. G. Agelidis, "Analysis of multicarrier PWM methods for a single-phase five level inverter," in Proc. Power Electron. Specialists Conf., 2001, vol. 3, pp. $1351-1356$

[5] C. T. Pan, C. M. Lai, and Y. L. Juan, "Output current ripple-free PWM inverters," IEEE Trans. Circuits Syst. II, Exp. Briefs., vol. 57, no. 10, pp. 823-827, Oct. 2010.

[6] T. C. Neugebauer, D. J. Perreault, J. H. Lang, and C. Livermore, "A six-phase multilevel inverter for MEMS electrostatic induction micro-motors," IEEE Trans. Circuits Syst. II, Exp. Briefs, vol. 51, no. 2, pp. 49-56, Feb. 2004.

[7] A. Nabae, I. Takahashi, and H. Akagi, "A new neutral-point-clamped PWM inverter," IEEE Trans. Ind. Appl., vol. IA-17, no. 5, pp. 518-523, Sep. 1981.

[8] M. F. Escalante, J. C. Vannier, and A. Arzandé, "Flying capacitor multilevel inverters and DTC motor drive applications," IEEE Trans. Ind. Electron., vol. 49, no. 4, pp. 809-815, Aug. 2002.

[9] M. Malinowski, K. Gopakumar, J. Rodriguez, and M. A. Pérez, "A survey on cascaded multilevel inverters," IEEE Trans. Ind. Electron., vol. 57, no. 7, pp. 2197-2206, Jul. 2010.

[10] M. R. Nayak and S. A. Mujeer, "New Computational Method for Study of Ionic Current Environment of HVDC Transmission Lines," 2020 IEEE International Conference on Advances and Developments in Electrical and Electronics Engineering (ICADEE), Coimbatore, India, 2020, pp. 1-5, doi: 10.1109/ICADEE51157.2020.9368934.

[11] S. N. Rao, D. V. A. Kumar, and C. S. Babu, "New multilevel inverter topology with reduced number of switches using advanced modulation strategies," in Proc. Int. Conf. Power, Energy Control, Feb. 2013, pp. 693-699.

[12] N. A. Rahim, M. F. M. Elias, and W. P. Hew, "Transistor-clamped H-bridge based cascaded multilevel inverter with new method of capacitor voltage balancing," IEEE Trans. Ind. Electron., vol. 60, no. 8, pp. 2943-2956, Aug. 2013.

[13] M. Raja Nayak, I. Rahul, T.Santhosh Kumar, "Experimental Investigations to Study the Corona Generated Ionic Current Environment of HVDC \& HVAC Transmission Lines" Journal of Advanced Research and Dynamic Control, vol 11, NO.5, pp: 158-165, November 2019.

[14] M. Raja Nayak,P.V.SAditya, S.Kirankumar, M. NarayanaNayak "Optimization of Grading Rings for Suspension Type Composite Insulators used in UHVDC Transmission System", Journal of Advanced Research and Dynamic Control Systems, vol 10 special issue, pp: 25752580, November 2018

[15] E. A. Mahrous, N. A. Rahim, and W. P. Hew, "Three-phase three-level voltage source inverter with low switching frequency based on the two-level inverter topology," IET Electric Power Appl., vol. 1, no. 4, pp. 637-641, Jul. 2007.

[16] P. R. Kumar, R. S. Kaarthik, K. Gopakumar, J. I. Leon, and L. G. Franquelo, "Seventeen-level inverter formed by cascading flying capacitor and floating capacitor H-bridges," IEEE Trans. Power Electron., vol. 30, no. 7, pp. 3471-3478, Jul. 2015. 